\title{
IMPLEMENTING GIS TO IMPROVE HOSPITAL EFFICIENCY IN NATURAL DISASTERS
}

\author{
Seyed Payam Salamati Nia ${ }^{1}$ *, Udayagani Kulatunga ${ }^{1}$, Chika Udeaja ${ }^{1}$, Somayeh Valadi ${ }^{2}$ \\ ${ }^{1}$ Centre for Disaster Resilience at University of Salford, Greater Manchester, M5 4WT, United Kingdom \\ (s.p.salamatinia@edu.salford.ac.uk), ( u.kulatunga@salford.ac.uk) (c.e.udeaja@salford.ac.uk) \\ ${ }^{2}$ Azad University, Civil Engineering faculty, Hashtgerd, Iran-( valadi.civil@yahoo.com)
}

KEY WORDS: Disaster management, GIS, Hospital, Mitigation, Natural disasters, Preperdness

\begin{abstract}
:
Over the past decades, the number of natural disasters has been growing around the world. In addition to damaging communities and infrastructures, unexpected disasters also affect service providers such as hospitals and health centers. Markedly, hospital safety from disasters is a challenge in all countries. With disaster damage to health systems resulting in human tragedy, huge economic losses, devastating blows to developmental goals, and shaken social confidence. Ensuring that hospitals and health facilities are safe and secure from disasters depend on implementing an appropriate method to mitigate adverse impacts on hospitals during incidents. Thus, disaster management becomes even more significant, as the health sector has been particularly vulnerable to damages.

So, it is crucial to develop appropriate mitigation and adoption method for healthcare facilities, to withstand the natural disasters such as earthquakes and floods. A comprehensive disaster plan is required to ensure a prompt disaster response and coordinated management of a multi causality incident. The aim of this research is to systemically and critically review the importance of hospitals in disaster events and this research attempts to reach a basic understanding to mitigate the risk of disasters in hospitals and improve the continuity of health services during or after disaster events. For this study, secondary information was retrieved from the literature review and document review on sudden-onset natural disasters in different parts of the world was collected. This study found some challenges and deliverables for disaster managers that could mitigate the risk of a natural disaster's impact on a hospital. Accordingly, this research will evaluate the importance of disaster management for hospitals and the challenges that need to be considered during the disaster response.
\end{abstract}

\section{INTRODUCTION}

During the past 20 years, a lot of countries have been experienced a significant number of natural catastrophic disasters which have had global effects on nature and societies (Catarci, 2007). In 2014, natural disasters had devastating effects on the human society. Three hundred and twenty-four natural disasters caused the death of more than 7823 individuals, 140.7 million injured individuals, and 99.2 billion dollars financial damages. Asia has experienced the highest number of disasters (44.4\%) and naturally has had the highest number of victims (69.5\%) (GuhaSapir, 2015). During the past three decades until 2010, natural disasters in Iran annually caused the death of 3000 individuals and affecting 1.5 million individuals. In such a country enjoying such frequent natural disasters, informing, preparing, and managing disasters are significant points in the public health (Ardalan, 2013).

Due to these disasters, disaster planning based on few experiences and assumptions is changing into evidence-based planning (Koenig, 2009). Therefore, paying attention to the issue of health management in natural disasters in Iran and organizing the information and communication situation for rescuing victims, as well as doing comprehensive research on disasters in Iran, resulting in preparedness and more appropriate responses in cases of occurrence of such events (Tavakoli, 2013).

\section{THE CONCEPT OF DISASTER}

The World Health Organisation (2006) defines disaster as any occurrence that causes damage, ecological disruption, the loss of human life, or the deterioration of health and health services, on a scale sufficient to warrant an extraordinary response from outside the affected community or area. The disaster has been defined by many researchers; for example, it is identified by Burnham (2013) as an unforeseen event that is suddenly overwhelming. Furthermore, McEntire (2015) describes disaster as a destructive, deadly and disruptive incident that happens when a hazard connects with humans. In fact, disasters can happen abruptly and can be classified as a dangerous and calamitous incident, which overwhelms and disrupts infrastructures (Ardalan, 2013). From a different perspective, it can be described on a household scale, where a disaster can cause major sickness and social calamity, or an essential economic catastrophe (Shaluf, 2007). It is clear from the above definitions that a disaster causes damage not only to human lives but also to constructed entities (Rathore \& Gosney, 2015). However, there are two common points in all of the aforementioned descriptions, which are time and location; indeed, Al-Dahash et al. (2016) confirm that disasters are defined based on time and space. Also, Alexander (2003, cited by Al-Dahash et al., 2016) described the disaster as a combination of vulnerability, lack of measures, and hazards that require the implementation of appropriate measures for planning, and the use of appropriate resources in order to mitigate the adverse impacts. 
Scientists have pointed out that natural disaster occurrences have significantly increased and intensified in the last 30 years; in Figure 1, the statistics demonstrate the number of earthquakes across the world between 2000 and 2015. Although there are some similarities between definitions, such as time, space, and their unforeseen nature, there is no universal definition of disaster events (Shaluf et al, 2003). Disaster events may happen in two different types such as; natural, and manmade. In 2015, the total number of earthquakes with a magnitude of more than five in the Richter scale reached nearly 1600 . While the technology used to record and find the source of earthquakes has improved since the 20th Century, the ability of scientists to predict earthquakes or other natural disasters is still severely limited (Gulyaeva \& Arikan, 2016). Hence, in this study researcher efforts to will go deeper into natural disasters, and assess the impact of natural disasters especially earthquake and flood on hospitals

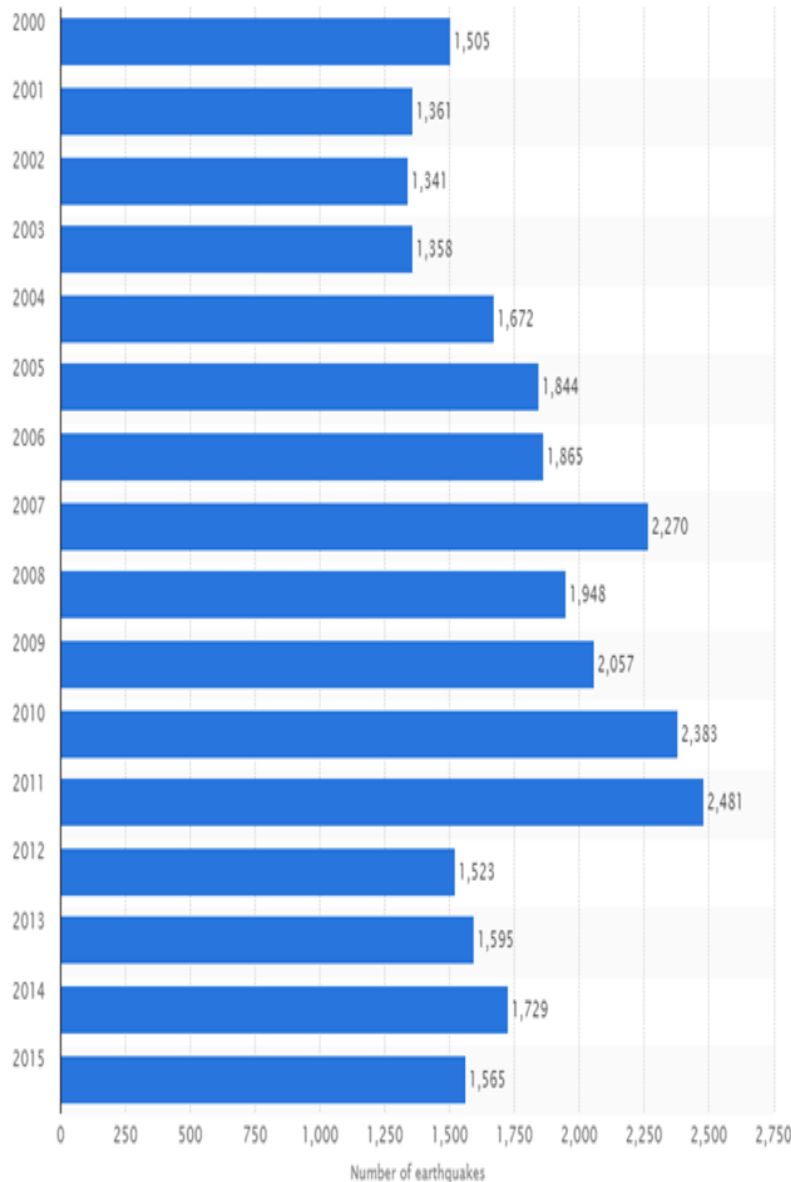

Figure 1: Development of the number of earthquakes (M5+) worldwide between 2000 and 2015(Gulyaeva \& Arikan, 2016)

Huder (2012) defined disaster events as a "pebble drop in a pond where the pebble impacts the surface of the pond and ripples outwards". In the case of a natural disaster, the impact is often felt throughout a community. A disaster can be an unforeseen event; it can overwhelm the capacities of those affected, and disrupt many normal human activities (Tomasini \& Van Wassenhove, 2004).
Many people are periodically exposed to at least one natural disaster in their life, and most disasters, or more correctly hazards that lead to disasters, cannot be prevented; however, their effects can be minimized (Lin Moe et al, 2006).

As communities worldwide face an increasing frequency and variety of disasters, there is an urgent need to reduce the risk from disasters (Lin Moe et al, 2006).

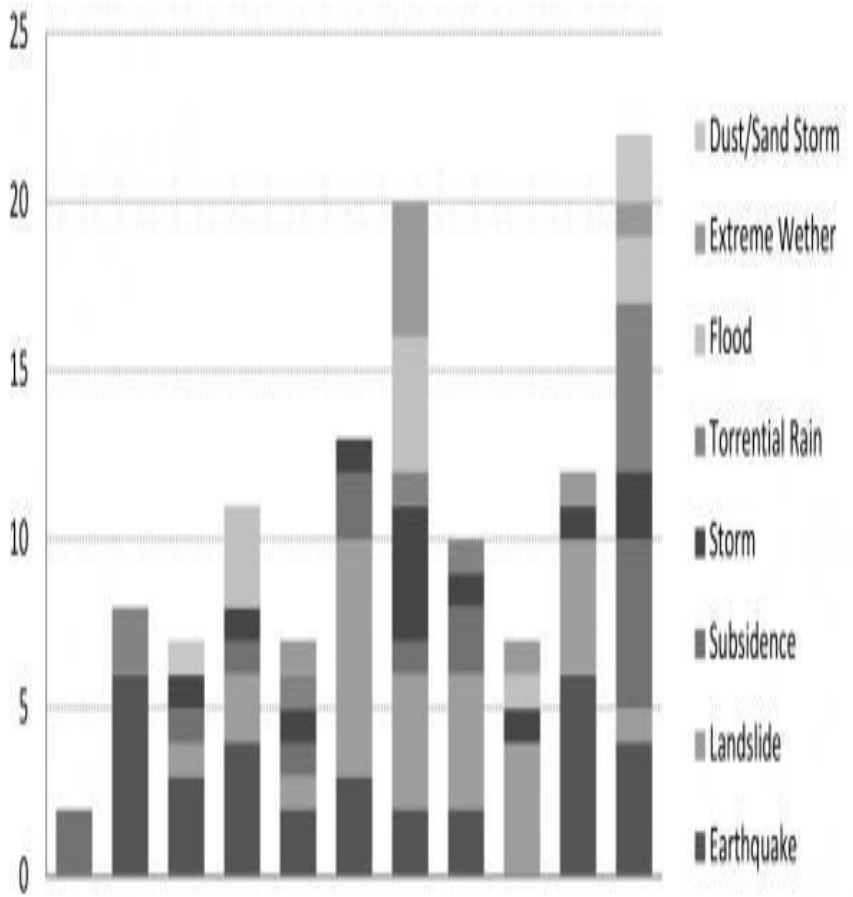

20012002200320042005200620072008200920102011

Figure 2: Occurrence of natural hazards with an impact on primary health care facilities, in Iran 2001-2011(Ardalan, 2013)

Within this context, disaster management is significant as it can mitigate some effects such efforts aim to reduce or avoid the potential losses from hazards, assure prompt and appropriate assistance to the victims of disaster, and achieve a rapid and effective recovery. Disaster management becomes even more important for hospitals as the health sector has been particularly vulnerable to disaster.

Health facilities, at all levels, deserve special attention in the case of natural disasters, as they must continue patient treatment and as well as care for those injured by the event (Eybpoosh, Dikmen, \& Talat Birgonul, 2011).

\section{CHALLENGES OF DISASTER MANAGERS IN HOSPITALS}

These studies require the existence of data and documented information about public health such as number of patients who have been cured, their release states, and types of diseases and injuries which have been cured after disasters in order that different reports needed for studies of disaster management in Iran, and particularly, epidemiological studies should be provided (Jahanbakhsh, 2011). Insufficiency in tracking casualties of Katrina Disaster in the USA was identified as a weakness in the planning of local and national preparedness for handling the event (Cook, 2007). 
After Bam Earthquake, Rathore stated that due to the insufficiency of patients' information, their management and effective assessment of their states were difficult (Rathore, 2013). Marres declared that facing great disasters needs a coordinated response of different organizations, but establishing coordination among organizations and geographically dispersed locations is a complicated process. One of the biggest challenges in such conditions is patient tracking. Mostly, there are no data about the number of victims, their conditions, their places, and their transfer (Marres, 2009). How hospitals respond to the demand for medical attention during and after a disaster event can be extremely challenging. Natural disasters impact on healthcare organizations and remind disaster managers to pay attention to the safety of their staff, particularly their first responders and physicians( Francescutti, 2017).

Usually, disaster managers in hospitals are faced with a range of challenges in such events, which include unexpected changes to newly injured or ongoing patient management, communication challenges, a lack of coordination, a lack of preparedness, and logistical deficiencies. For example, in August 2012, an earthquake occurred close to the cities of Ahar and Varzeghan in the East-Azerbaijan province in North-West Iran. This earthquake caused suffering for over 2 million people and forced many people to sleep outside for two nights.

The earthquake killed 327 people, claimed more than 3000 injuries, and left more than 30,000 people homeless. Buildings in the stricken area experienced different levels of damage; however, most of the adobe buildings in the villages had collapsed and several masonries and framed buildings were damaged. Furthermore, some of the roads were damaged due to the surface faulting and geotechnical instabilities (Razzaghi, 2012). Although some of the bridges suffered damage, they remained serviceable after the event. Nevertheless, many of the essential facilities, such as hospitals, in the stricken areas were damaged and some industrial plants experienced economic losses due to the unsafe shutdown process after the earthquake. The performance of the hospitals was not acceptable in that they were not operable after the disaster event. One particular example of this was the Bagher-aloom Hospital in Ahar city, which suffered remarkable non-structural damages and was put out of commission after the earthquake. In particular, the collapse of the infill walls and of the false ceilings, and the overturning of medical equipment were major failures in the non-structural components of the hospital (Salamati, 2017).

Due to such damage, treatment was carried out in temporary hospitals set up in tents, as it can be seen in Figure 1, and rescue teams had to transfer injured people to the hospitals in nearby cities. Heavy traffic jams in Tabriz-Varzaghan, Tabriz-Ahar and along other primary roads of the affected area caused significant trouble for the rescue teams, and the main reason for this was a large number of volunteers going to the affected areas to help the rescue teams. Thus, effective disaster planning could have mitigated some of the potential damage of this natural disaster, and provide a better health service during and after a disaster to patients in the worst affected hospital. In the following sections, some specific challenges of disaster managers will be explained (Razzaghi, 2012).

\section{METHODOLOGY}

This research is based on secondary data analysis that defines and explains disaster impacts on hospitals and reviews some challenges facing hospital disaster managers in the light of natural disaster events. The data have been gathered from peerreviewed journals, and some books and conference papers.
Databases were used to gather information regarding: the context of disaster management in hospitals, the local pre-disaster availability of hospitals and health facilities, and the sudden impact of natural disasters on hospitals. For this phase of the study, a qualitative content analysis will form the major research instrument to analyses the secondary data. At this point, the primary data collection and analysis has not yet been completed, which will collect by interview relevant expert views regarding hospital disaster management. This current paper will thus purely adopt a qualitative data collection strategy, and consider a variety of secondary sources accessed through the Internet and academic databases.

\section{DISCUSSION}

Before any disaster events, the appropriate data has to be gathered, organized and displayed logically to determine the size and scope of emergency management programs. During an actual emergency, it is critical to have the right data, at the right time, displayed logically, to respond and take appropriate action. Emergencies can impact all or a number of government departments. Emergency personnel often need detailed information concerning pipelines, building layout, electrical distribution, sewer systems, and so forth. By utilizing a GIS, all departments can share information through databases on computer-generated maps in one location (Tavakoli, 2016). Without this capability, emergency workers must gain access to a number of department managers, their unique maps, and their unique data. Most emergencies do not allow time to gather these resources. This results in emergency responders having to guess, estimate, or make decisions without adequate information. This costs time, money, and in some cases lives. GIS provides a mechanism to centralize and visually display critical information during an emergency. Most of the data requirements for emergency management are of a spatial nature and can be located on a map (Johnsin, 2000).

Emergency management programs begin with locating and identifying potential emergency problems. Using a GIS, officials can pinpoint hazards and begin to evaluate the consequences of potential emergencies or disasters. When hazards (earthquake faults, fire hazard areas, flood zones, shoreline exposure, etc.) are viewed with other map data (streets, pipelines, buildings, residential areas, power lines, storage facilities, etc.), emergency management officials can begin to formulate mitigation, preparedness, response, and possible recovery needs. Lives, property, and environmental values at high risk from potential emergency or disaster become apparent.

Public safety personnel can focus on where mitigation efforts will be necessary, where preparedness efforts must be focused, where response efforts must be strengthened, and the type of recovery efforts that may be necessary. Before an effective emergency management program can be implemented, thorough analysis and planning must be done. GIS facilitates this process by allowing planners to view the appropriate combinations of spatial data through computer-generated maps(Sutton, 2006). As potential emergency situations are identified, mitigation needs can be determined and prioritized. In the case of an earthquake, what developments are within the primary impact zone of earthquake faults?

Based on the expected magnitude of an earthquake, characteristics of soils, and other geologic data, what damage may occur? What facilities require reinforced construction or relocation? What facilities are in high hazard areas (key bridges, primary roads, freeway overpasses, hospitals, hazardous material storage facilities, etc.)? Mitigation may include implementing legislation that limits hospital building in earthquake or flood zones. 
Other mitigation may target fire-safe roofing materials in wildland fire hazard areas. Values at risk can be displayed quickly and efficiently through a GIS. Utilizing existing databases linked to geographic features in GIS makes this possible (Lock, 2018). Where are the fire hazard zones? What combination of features (for example, topography, vegetation, and weather) constitutes a fire hazard? A GIS can identify specific slope categories in combination with certain species of flammable vegetation near hospitals that could be threatened by wildfire.

A GIS can identify certain soil types in and adjacent to earthquake impact zones where bridges or overpasses are at risk. A GIS can identify the likely path of a flood based on topographic features or the spread of a coastal oil spill based on currents and wind. More importantly, human life and other values (property, habitat, wildlife, etc.) at risk from these emergencies can be quickly identified and targeted for protective action. Preparedness includes those activities that prepare for actual emergencies. GIS can provide answers to questions such as Where should fire stations be located in distance with hospitals if a five minute response time is expected? How many paramedic units are required and where should they be located? What evacuation routes should be selected if a toxic cloud or plume is accidentally released from a plant or storage facility based on different wind patterns? How will people be notified? Will the road networks handle the traffic? What facilities will provide evacuation shelters? What quantity of supplies, bed space, and so forth, will be required at each shelter based on the number of expected evacuees? GIS can display real-time monitoring for emergency early warning. Remote weather stations can provide current weather indexes based on location and surrounding areas. Wind direction, temperature, and relative humidity can be displayed by the reporting weather station (VanVactor,2017). Wind information is vital in predicting the movement of a chemical cloud release or anticipating the direction of wildfire spread upon the early report. Earth movements (earthquake), reservoir level at dam sights, radiation monitors, and so forth, can all be monitored and displayed by location in GIS. It is now possible to deliver this type of information and geographic display over the Internet for public information or the Intranet for organizational information delivery. GIS can provide one of the primary components for computer-aided dispatch (CAD) systems.

Emergency response units based at fixed locations can be selected and routed for emergency response (Schneider, 2018). The closest and quickest response units can be selected, routed, and dispatched to an emergency once the location is known. Depending on the emergency, a GIS can provide detailed information before the first units arrive. For instance, during a commercial building fire, it is possible to identify the closest hydrants, electrical panels, hazardous materials, and floor plan of the building while end route to the emergency. For hazardous spills or chemical cloud release, the direction and speed of movement can be modeled to determine evacuation zones and containment needs.

\section{CONCLUSION}

In conclusion, preparing a hospital for a natural disaster event is important as it is likely to face high demand from injured people. Whether disasters are from flooding, hurricanes, severe heat waves, droughts, ice storms, tornadoes, typhoons, or fires are less significant than the need to respond quickly, appropriately, and with authority.
The main issues are that firstly, there is no clear way to predict when a natural event will occur, and secondly that it will be difficult to determine about any potentially destructive trajectories. Nevertheless, it is important to prepare a hospital by maintaining its condition and learning from previous disaster events in order to mitigate the risk of hazards. In conclusion, it is crucial to have right disaster management plan in place to avoid and mitigate the risk of a disaster incapacitating a hospital. Hospital disaster managers have a critical role in keeping hospitals in a good condition as they provide the most strategic location in terms of relief in natural disaster events. Disaster managers may face a lack of coordination, and communication and logistics issues, which, as well as addressing at the time, should be considered as valuable learning for future disaster management plans.

Disasters are not likely to decrease in the foreseeable future; therefore, a sustained effort is needed to minimize risk by reducing vulnerability through prevention and mitigation and by increasing capacity through preparedness measures. In previous experiences, such as earthquakes, floods, or tsunamis, the importance of hospitals have been critically important. Previous strategies employed by health authorities and relief groups to reduce further morbidity and mortality following natural disasters may be helpful in similar future events; however, this must be comprehensively evaluated for each disaster plan. Due to the geographical and geological situation of these previous incidents, it could be argued that further disaster events are inevitable. Nevertheless, many lessons should be learned from previous natural disaster events and how planning could be applied to future incidents.

Therefore, planning for natural disasters depends on the type and magnitude and its consequent impact on hospitals' water and food supplies, sewage systems, access to buildings, access to patients' documents, and medical supplies. The immediate health burden depends on the nature of the hazard. In the aftermath of a major disaster, authorities must meet extraordinary demands with resources that might not begin to meet even basic health needs and that often have been drained by the immediate emergency response. Disasters related to natural events may affect the transmission of pre-existing infectious disease, but the imminent risk of large outbreaks in the aftermath of natural disasters is often overstated. Therefore, comprehensive and effective disaster management is highly important for hospitals and health centers. During a disaster, it may become necessary to evacuate nonambulant and ambulant patients; thus the response to disaster including evacuation procedures should be well established.

\section{REFERENCES}

Al-Dahash, H., Thayaparan, M., \& Kulatunga, U. (2016). Understanding the terminologies: disaster, crisis, and emergency. Management, 2, 1191-1200.

Alexander, D. E. (2003). Principles of emergency planning and management: Oxford University Press on Demand.

Ardalan A, Mowafi H, Malekafzali Ardakani H, Abolhasanai F, Zanganeh AM, Safizadeh H, et al. Effectiveness of a primary health care program on urban and rural community disaster preparedness, Islamic Republic of Iran: A community intervention trial. Disaster Med Public Health Prep 2013;7:48190.

Ardalan, \& Schnelle, D. D. (2016). Chapter 93 - Introduction to Natural Disasters A2 - Ciottone, Gregory R Ciottone's Disaster Medicine (Second Edition) (pp. 566-568). Philadelphia: Elsevier. 
Burnham, E,. Gilbert M C. R. (2013). John Hopkins and the international federation of Red Cross and Red Crescent societies Public Health Guide for Emergencies. Retrieved from www.jhsph.edu/research/.../Public_Health_Guide_for_Emergen cies Catarci T, Mecella M. D1. 1 Project Presentation. 2007.

Dobson I, Doan Q, Hung G. A systematic review of patient tracking systems for use in the pediatric emergency department. J Emerg Med 2013;44:242-8. Marshall I Jr., Mathews S. Disaster preparedness for the elderly: An analysis of international literature using symbolic interactionist perspective. J Aging Emerg Econ 2010;2:79-92.

Guha-Sapir D, Hoyois P, Below B. Annual Disaster Statistical Review 2014 - The Numbers and Trends ed Nation. Belgium, 2015.

Huder, R. C. (2013). Disaster operations and decision making: John Wiley \& Sons.

Iran, Islamic Rep of - Disaster Statistics 2014. Data Related to Human and Economic Losses from Disasters that have Occurred between 1980 and 2010. Available from: http://www.preventionweb.net/english/countries/statistics. [Last cited on 2014 Nov 22]. Koenig KL, Schultz CH. Koenig and Schultz's Disaster Medicine: Comprehensive Principles and Practices. UK: Cambridge University Press; 2009.

Government Report, Emergency Operation Center, Ministry of Health, Tehran, 2010. Tomasini, R. M., \& Van Wassenhove, L. N. (2004). Pan-American health organization's humanitarian supply management system: de-politicization of the humanitarian supply chain by creating accountability. Journal of public procurement, 4(3), 437 .

Tavakoli N, Jahanbakhsh M, Fooladvand M. Developing health information documentation in disaster. Int J Health Syst Disaster Manage 2013;1:11.

Gulyaeva, T. L., Arikan, F., \& Stanislawska, I. (2017). Earthquake aftereffects in the Equatorial Ionization Anomaly region under geomagnetic quiet and storm conditions. Advances in Space Research.

Jahanbakhsh M, Tavakoli N, Hadadpour A. Designing disaster victims' medical record; a step toward crisis management. Health Inf Manage 2011;16:400-9. Johnson, R. (2000). GIS technology for disasters and emergency management. An ESRI white paper.

Cook DJ, Das SK. How smart are our environments? An updated look at the state of the art. Pervasive Mob Comput 2007;3:53-73. VanVactor, J. D. (2017). Healthcare logistics in disaster planning and emergency management: A perspective. Journal of business continuity \& emergency planning, 10(2), 157-176.

Rathore FA, Gosney JE, Raissi GR, Li J. Experience and preparedness of major incidents in developing countries. Disaster Med Public Health Prep 2013;7:127-8

Marres G, Bemelman M, van der Eijk J, Leenen L. Major incident hospital: Development of a permanent facility for the management of incident casualties. Eur J Trauma Emerg Surg 2009;35:203-11.

McEntire, D. A. (2014). Disaster response and recovery: Strategies and tactics for resilience: John Wiley \& Sons.
Schultz CH, Koenig KL, Noji EK. A medical disaster response to reduce immediate mortality after an earthquake. N Engl J Med 1996;334:438-44.

Carlton M. Surge capacity management and patient identification in disaster preparedness. Elsevier Health Sciences, 2006.

Sutton, J., \& Tierney, K. (2006, November). Disaster preparedness: concepts, guidance, and research. In Fritz Institute Assessing Disaster Preparedness Conference.

Rich T, Biddinger P, Zane R, Hassol A, Savitz L, Warren M. Recommendations for a National Mass Patient and Evacuee Movement, Regulating, and Tracking System. Contract No.: Contract No. 290-00-0003, Task Order No. 12. USA: Agency for Healthcare Research and Quality; 2005.

Razzaghi, M.S. \& Ghafory-Ashtiany, M., A preliminary reconnaissance report on August 11th, 2012, Varzaghan-Ahar twin earthquakes in NW of Iran. Report of International Association of Seismology and Physics of the Earth's Interior, 2012.

Salamati, N., Kulatunga, U., \& Thayaparan, M. (2016). The Importance of Disaster Management and Impact of it into Hospitals. Paper presented at the SPARC 2016, Media City UK.

Salamati Nia, S. P., \& Kulatunga, U. (2017). The importance of disaster management and impact of natural disasters on hospitals.

Salamati Nia, S. P., \& Kulatunga, U. (2017). The challenges of hospital disaster managers in natural disaster events.

Schneider, S. K. (2018). Governmental Response to Disasters: Key Attributes, Expectations, and Implications. In Handbook of Disaster Research (pp. 551-568). Springer, Cham.

Shaluf, I. M. (2007). Disaster types. Disaster Prevention and Management: An International Journal, 16(5), 704-717. Doi: doi: $10.1108 / 09653560710837019$

Francescutti, L.H., Sauve, M. \& Prasad, A.S., Natural disasters, and healthcare: Lessons to be learned. In Healthcare Management Forum 2017 (Vol. 30, No. 1, pp. 53-55). Sage Publications, Los Angeles, CA, 2017.

Tavakoli, N., Yarmohammadian, M. H., Safdari, R., \& Keyvanara, M. (2016). Health sector readiness for patient tracking in disaster: A literature review on concepts and patterns. International Journal of Health System and Disaster Management, 4(3), 75. 